\title{
Technology for Situated and Emergent Play: A Bridging Concept and Design Agenda
}

\author{
Ferran Altarriba Bertran \\ UC Santa Cruz \\ Santa Cruz, CA \\ ferranaltarriba@gmail.com
}

\author{
Elena Márquez Segura \\ Uppsala University \\ Uppsala, Sweden \\ elena.marqz@gmail.com
}

\author{
Katherine Isbister \\ UC Santa Cruz \\ Santa Cruz, CA \\ kisbiste@ucsc.edu
}

\begin{abstract}
Despite the capacity of play to spontaneously emerge in our daily life, the scope of application of play design in HCI is generally narrower, specifically targeting areas of pure leisure, or wholly utilitarian and productive play. Here we focus on the value of play design to respond to and support our natural gravitation towards emergent play that helps to meet our social and emotional needs. We present a bridging concept: Technology for Situated and Emergent Play, i.e. technology design that supports playful engagement that emerges interwoven with our everyday activities outside leisure, and that enriches these activities with socioemotional value. Our intermediate-level contribution has value as a synthesis piece: it weaves together theories of play and play design and bridges them with concrete design examples. As a bridging concept, it contributes: i) theoretical grounding; ii) inspiring design exemplars that illustrate the theory and foreground its value; and iii) design articulations in the form of valuable experiential qualities and design features. Our work can help to focus design agendas for playful technology and inspire future designs in this space.
\end{abstract}

\section{Author Keywords}

Play; Playfulness; Interaction Design; HCI.

\section{CCS Concepts \\ - Human-centered computing $\rightarrow$ HCI theory, concepts and models}

\section{INTRODUCTION}

The interest of the Human-Computer Interaction (HCI) community in play and games is growing and transcends the scope of purely entertainment games. Play is often used to craft compelling technology-mediated experiences $[19,25,37,45,54]$. Researchers are investigating how to incorporate play's desirable experiential qualities in mundane situations [45,54], and how to design porous magic circles where play is intertwined with everyday activity [25].

A common approach to play design in HCI is to leverage the motivational power of games and play in service of Permission to make digital or hard copies of all or part of this work for personal or classroom use is granted without fee provided that copies are not made or distributed for profit or commercial advantage and that copies bear this notice and the full citation on the first page. Copyrights for components of this work owned by others than the author(s) must be honored. Abstracting with credit is permitted. To copy otherwise, or republish, to post on servers or to redistribute to lists, requires prior specific permission and/or a fee. Request permissions from permissions@acm.org.

CHI '20, April 25-30, 2020, Honolulu, HI, USA.

(C) 2020 Copyright is held by the owner/author(s). Publication rights licensed to ACM. ACM ISBN 978-1-4503-6708-0/20/04...\$15.00

DOI: https://doi.org/10.1145/3313831.3376859 productivity [71]. For example, playful technology is used to support and optimize task-oriented activities (e.g. serious games [59] or gamification [19]) in a myriad of domains, e.g. health [41], learning [86], or the workplace [13]. But there are other values that play design can bring to society beyond performance and productivity. Play is a fundamental aspect of human life [81] and culture [42], the essence of life and something desirable even when it is not materially productive [79]. We argue that designing technology that supports this kind of play offers a necessary counterbalance to the pervasive focus of others on productivity, which has crept into every sphere our lives [30,31].

Here, we focus on the value of play as it emerges intertwined with and seasoning our everyday activities, positively impacting the player socially and emotionally. We center on technologies that populate this design space and investigate how they support this kind of playful engagement. We characterize this design space through a bridging concept [16] intermediate-level knowledge form [53], namely Technology for Situated and Emergent Play. This bridging concept can facilitate the design of technology for playful engagement: i) that is well rooted in real-life activities and contexts and supports - rather than disrupts - going about one's life without having to step out of everyday business and into a dedicated play circle; ii) that is flexible, open, and player-motivated; and iii) that enriches daily activities and has socio-emotional value for the player, e.g. supporting the player to build stronger social bonds; feel free, explorative and creative; or simply experience joy and affect.

Our bridging concept characterizes a design space that has received less attention than others in play-related HCI. It has synthetic and inspirational value: it weaves together a body of theoretical works on the socio-emotional importance of playful engagement, and concrete, illustrative, and inspirational design exemplars. As a bridging concept, we ground it: First, theoretically [16] with literature from within and outside of HCI; Then, through design exemplars [16]: a collection of 13 designs that illustrate how technology can season the experiential texture of everyday activities with playfulness; Last, through two design articulations that bridge theory and exemplars [16], surfacing important experiential qualities of play, and unpacking supporting design features. This can inspire technology design in ways that are currently under-represented in HCI. 
Our work resonates with existing trends in HCI (e.g. slow technology [33] or somaesthetics $[39,40]$ ) that build on the idea that technology can contribute to making our lives worth living. In particular, we add to works focused on everyday play and playfulness (e.g. $[2,6,25])$ and works that aim at play that supports the player socially and emotionally (e.g. $[44,72])$. With this paper, we work towards making accessible a body of theoretical and design knowledge that can inspire designers to create playful technologies that better respond to people's social and emotional needs.

\section{BACKGROUND}

Here we set the theoretical foundation of our work and motivate the design space and design agenda of designing Technology for Situated and Emergent Play. We will introduce relevant concepts in HCI, Play Studies and Play Design, and position our contribution within previous work.

\section{Play and Human Life}

Humans are not productivity tools - we are creatures motivated by pleasure, by social and emotional connection, by agency, and by positive feelings [8]. Play can be a way to bring these properties into the systems we build. Sharp and Thomas call this the eudaimonic function of play: even if it does not yield materially productive results, play can be considered socially and emotionally productive [71].

The idea that daily-use technologies can be playful can be in tension with contemporary trends placing productivity and performance at the core of human fulfilment $[9,71]$. That presents a conundrum, as play, "the space within which we experience the world above and beyond utility" [71], is known to be an important factor for both personal and societal well-being $[7,10,42]$. Too much emphasis on productivity, progress, and future rewards may risk not being focused on, engaged with, and enjoying the present [70]: "In seeking to spend life as productively as we can, we bring upon ourselves the ultimate ironic punishment: we miss it" [9]. Stuart Brown, a medical doctor with a longstanding commitment to play therapy, explains the negative aspects of playlessness: "When play is denied over the long term, our mood darkens. We lose our sense of optimism and we become incapable of feeling sustained pleasure" [7]. Burkeman argues for the value of play as an "antidote to this disease" [9]. Ash Perrin, a clown volunteering in refugee camps, also stresses the relevance of everyday play: "In this world we live in, we really need to squeeze in more play. Play in your workplace, $[\ldots]$ in your home, $[\ldots]$ in the car, $[\ldots]$ in the supermarket. At the very least, what you'll find is a few more smiles in a few more faces. But at the very most, you may just change somebody's perspective on who they are and change their lives." [63]. Sicart adds to this with his "call to playful arms against technical determinism" [72], stressing the need to design technology that enables us to experience everyday play as it responds to basic human needs [72].

\section{The State of Play in $\mathrm{HCl}$ : Dominant Approaches}

Play is gaining traction in $\mathrm{HCI}$ and Interaction Design (IxD). Several works in this space investigate play as focused entertainment, exploring the intrinsic value of play and games as non-instrumental, self-contained activities [58]. But the interest of HCI in play and games is growing and transcends the scope of pure entertainment. Researchers also investigate how to leverage the desirable qualities of play in mundane situations and how to design porous magic circles [78] where play intertwines with everyday activity. Within that space, a noteworthy body of works explore how to leverage play as a means to a productive end - where the aim is to support productive outcomes in "serious" domains, e.g. learning, health, or well-being. Generally speaking, works in this area include serious games [59]; games4Health [84]; games for learning [32]; and gamification designs (e.g. [68]).

Using play to motivate, engage and support utilitarian goals seems to be a more popular research agenda than exploring its socio-emotional value. While this trend has not yet been proven quantitatively, it is noted by many. For example, focusing on exergames-games involving physical exertion-Marshall et al. criticize an excessive focus on promoting measurable exercise-related outcomes (e.g. losing weight) to the detriment of the experience [56]. Linehan et al. argue that Games4Health often "instrumentalize game design" to promote behavior change, an approach that is clearly outcome-oriented and sees the "player as a deficient entity in want of repair" [51]. Rey suggests that the basic appeal of gamification is that it "spur[s] economic activity" by "influencing the behavior of producers and consumers," "implod[ing] play into work", and "mak[ing] exploitation easier" [65]. Sharp and Thomas suggest that utilitarian approaches to play design in HCI reflect a contemporary post-industrial culture that "downplays emotions" and "looks down upon play and its affective productivity" [71]. Burkeman seconds that idea: "in a society fixated on productivity [...], even temporarily rejecting those values in order to spend time playing can be a radical act" [9].

\section{Social and Emotional Approaches to Playful $\mathrm{HCl}$}

The "exploitation" [6] of play towards productivity has been criticized by many: First, it leads to overly optimistic understandings of the potential of play to address real-life problems [56]. Second, it raises ethical concerns as it manipulates people into doing tasks they might not want to do [6,62]. Third, and most importantly, it can blind us from: seeing the rich spectrum of forms play can take [71]; understanding its socio-cultural relevance [81]; and, in particular, exploring how it can respond to personal and societal needs for wonder, joy and social connection [21].

Today's focus on the utilitarian value of play is at odds with the vision that technology should allow us to engage more with leisure [67] and "pursue our lives, not just work" [25]. Researchers propose inspiring alternative concepts that embrace a more diverse idea of play and focus more on the quality of the experience than on its productivity goals. Bogost proposes to transform the world into a playground through playful re-signification, treating "anything with the deliberate attention that produces fun" [6]. Similarly, 


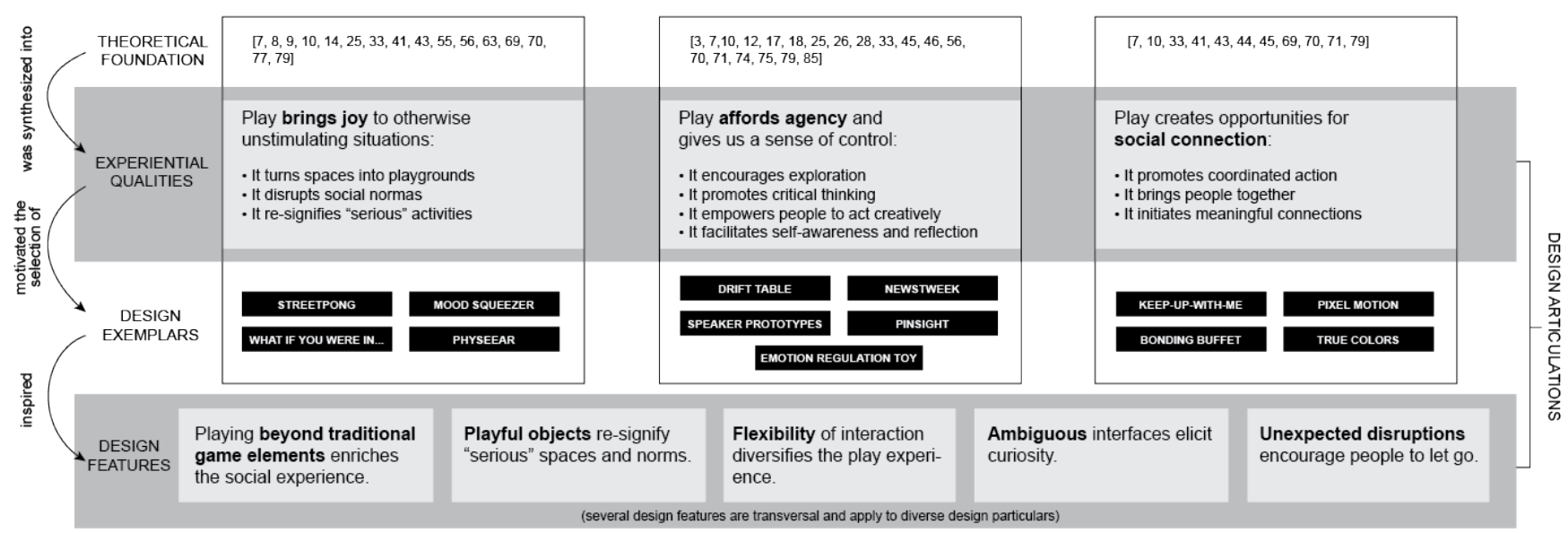

Figure 1. The 'Technology for Situated and Emergent Play' bridging concept and its constituents: a theoretical foundation; two design articulations in the form of experiential qualities and design features; and a collection of design exemplars.

Burkeman suggests that we could "allow the spirit of play to suffuse our telic tasks" [9], which Playification implements in goal-oriented tasks (e.g. therapy [54]). As opposed to the criticized productivity-focused gamification [83], playification values the quality of the play experience at least as much as (if not more than) the out-of-play goals. Gaver's ludic design uses open-ended technologies that invite exploration and support experiences people long for, beyond helping them "get the chores done" [25]. The work of Isbister [45] and Márquez Segura et al. [55] on co-located play is also inspiring: it presents valuable social affordances for technology-i.e. pro-social behavior that is supported by design elements - inspired by or targeting play design. Castelhano and Roque offer strategies to promote playful engagement in multi-sensory environments [11]. Inspired by these works, we argue that, in a world where technology is increasingly present, functional and productive; it is equally important to also support the socio-emotional value of play. Here we foreground this value, and help designers embrace it in their own work through a bridging concept.

\section{Inspirational Collections and Intermediate-Level Work}

This paper is not the first that presents a collection of playful technologies foregrounding the socio-emotional value of play and/or proposing relevant design features. Sicart's Play Matters [72], a "manifesto with footnotes" [19], advocates for the importance of everyday play as a key part of life. Despite its theoretical focus, it illustrates different ways in which play matters through inspiring descriptions of real designs. It also contributes with concepts that are key to understanding the porous nature of playfulness, since it is "an attitude that allows us to experience play in activities that are not play." [72] From games and play design, Isbister's How Games Move Us [44] examines the socioemotional relevance of games and shows with examples the benefits that social, co-located, and physical play can have on people's emotions. From IxD, Gaver's ludic design [25] shows how playful interfaces can promote curiosity and exploration, and offers insights on how to design them. Hobye's $\mathrm{PhD}$ thesis [37] is a manifesto proposing strategies to support explorative and performative play in social contexts.

These works show concrete values of play as a social good, e.g. Isbister et al.'s work on the social affordances of play [45]. Some also unpack design strategies to promote specific kinds of playful engagement, e.g. Gaver et al.'s ambiguity [26]. Here we build on, and synthesize, these contributions through a bridging concept [16], characterizing an important design space through a set of design articulations. They take the form of experiential qualities of play and design features, which we bridge with theories within, and outside HCI. The design cases, and the inspirational design features we unpack, concretize those theories and make them more actionable.

\section{METHOD}

Bridging concepts are intermediate-level knowledge forms residing at a level of abstraction between theory and practice. They facilitate the exchange between them "articulat[ing] untried design opportunities and potential theoretical advancements." [16] Bridging concepts, like ours, have three main components: "a theoretical foundation, a set of design articulations and a range of exemplars that demonstrate the scope and potential of their application." [16] They can be created bottom-up (i.e. starting with a strong concept [38] grounded in design exemplars, which is then linked to theory), or top-down (i.e. starting with conceptual constructs, which are concretized with design exemplars).

Our concept was derived from two characterizing traits of playful engagement that takes place within mundane activities: it is situated, i.e. it takes place in non-play contexts and intertwined with non-play activity, and is therefore contingent on the idiosyncrasies of non-play scenarios; and it is emergent, i.e. it emerges organically as people playfully re-ambiguate mundane situations. We created it following a top-down approach (see Figure 1) with the goal of making accessible a set of theories to designers. Consistent with that approach, we deliberately chose exemplars that could help illustrate and concretize those theories. We began with the 

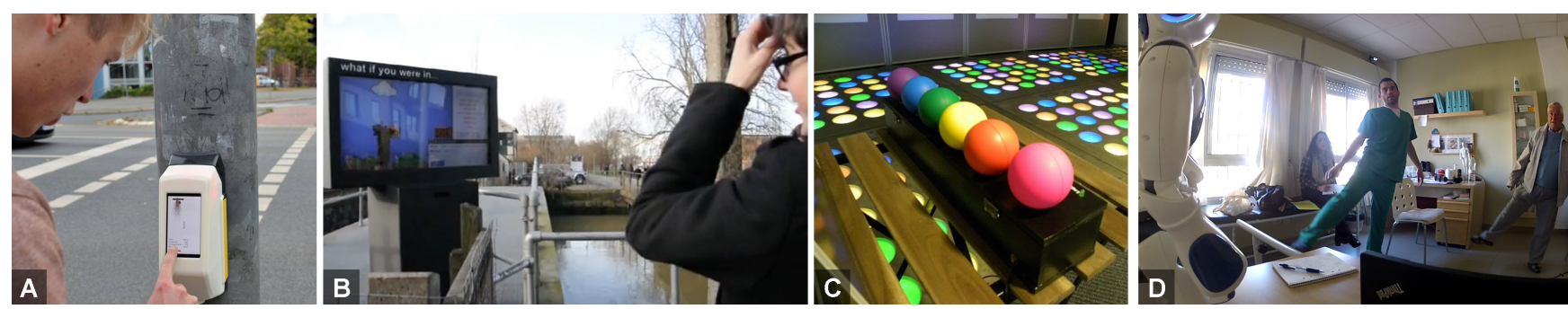

Figure 2. Playful technologies that are a source of positive affect. A: StreetPong [21]. B: What If You Were In...[1]. C: the Mood Squeezer [24] spheres and LED floor. D: inpatient and a caregiver interacting with PhySeEar [54].

theoretical foundation, reviewing literature from diverse areas of play scholarship (game studies, sociology, philosophy, play design, cultural studies, and psychology) related to: i) play that is well rooted in real-life activities and contexts, and that supports - rather than disrupts - going about one's life without having to step out of everyday business and into a dedicated play circle; ii) play that emerges, is flexible, open, and player-motivated; iii) and play that enriches daily activities and has socio-emotional value for the player, e.g. supporting the player to build stronger social bonds; feel free, explorative and creative; or simply experience joy and affect. These foci characterize the design space that our bridging concept encapsulates, and narrowed down our investigation and search of literature, and later design exemplars.

Our design articulations take two forms: experiential qualities of play, and design features of play(ful) technology. First, we conducted a thematic analysis of the literature, compiled to identify emerging and recurrent themes. We clustered our findings into three experiential qualities of play that support desirable societal values. Second, we searched for inspirational design practice in HCI showing how playful technology can support people socially and emotionally. We selected 13 design exemplars for how they resonated with and illustrated well those experiential qualities. Our analysis of the exemplars surfaced 5 recurrent design features that can inspire future technology designs that leverage the socioemotional relevance of play.

\section{EXPERIENTIAL QUALITIES OF PLAY: PLAYFUL TECHNOLOGIES WITH SOCIO-EMOTIONAL VALUE}

Here, we foreground, unpack, and illustrate three desirable experiential qualities of play that emerged in our review of play scholarship: (1) bringing joy to otherwise unstimulating situations; (2) empowering and supporting agency; and (3) promoting social connection. We also introduce the design exemplars, which serve to illustrate these qualities.

\section{Play Brings Joy to Otherwise Unstimulating Moments}

One of the most obvious effects of play is that it generates positive emotions [7]: it is intensely pleasurable; it speaks to our inner desire of joy and stimulation; it can be a source of fun and laughter; it can make us thrive. Here we discuss three ways in which playful technology can bring joy: i) turning

\footnotetext{
${ }^{1}$ Video of StreetPong: https://bit.ly/1kAwMzk
}

serious spaces into playgrounds; ii) disrupting socio-cultural norms; and iii) re-signifying activities into playful ones.

It is commonly said that, when playing, "time flies." Play is a "cure for boredom" that "eases our burdens" [7]: it puts us in a state of flow where we are deeply immersed in, and profoundly enjoy, whatever we are doing [14]. Playful technology can help us season the countless playless situations we often experience every day by turning spaces into playgrounds. A design exemplar that illustrates this quality is StreetPong ${ }^{1}$ [21] (Figure 2A), a touchscreen device attached to traffic light poles that allows pedestrians to play Pong with one another while waiting for the green light. It turns a seemingly long wait into a seemingly short moment of fast-paced social competition. Similarly, What If You Were In $^{2}$ [1] (Figure 2B) can make waiting at train level crossings more enjoyable by offering passersby a chance to escape and travel elsewhere: users can send a text choosing a place where they would rather be, and they will see themselves at the desired location on a screen. Both designs show how playful technology can transform "serious" spaces, turning boring situations into stimulating experiences that "enliven us" [7] and make time fly. They create a porous circle of play that, while not removing players completely from the situation, is experientially rich and gives them a chance to detach from feelings of boredom and frustration.

Playful technology can also help us re-frame the social norms that regulate our routines. "Serious" contexts, e.g. the workplace or a medical setting, tend to not only discourage play, but at times also self-expression and social bondingboth considered basic human needs [7]. Through play we can reclaim those needs, create space for self-expression [56], and "personalize the world, making it ours while still acknowledging that it has a purpose other than playing" [44]. A design exemplar that illustrates this quality is Mood Squeezer [24] (Figure 2C): it allows people to express their mood by squeezing colored balls, which light up an LED floor in different colors. Designed to "provide an injection of playfulness" into workplace settings [24], it brought about significant results: it improved the quality of conversations, becoming an "ice-breaker in awkward situations"; it helped people be "more open about how they felt"; and "it liven[ed] the place up", while keeping the workspace productive.

\footnotetext{
${ }^{2}$ Video of What If You Were In: https://bit.ly/2GJUYnG
} 
Inviting frivolous play [81] in serious settings can lead to more productive and satisfying work [57]. For example, in PhySeEar [54] (Figure 2D), a robot designed to assist in rehabilitative physical exercises was also used to improve the experience of inpatients and physiotherapists. Building on the robot's behavior, they could playfully re-signify the sessions by siding together and antagonizing the robot, blaming it for the negative aspects of their personal roles and performance. For example, the robot (rather than the therapist who had ultimate control over it) was playfully blamed for being too strict providing feedback; or the robot (rather than the inpatients to whom it mimicked) was playfully blamed for negative aspects of the physical performance. Playing with the robot led to positive physical, emotional, and social results: it strengthened bonds between inpatients and therapists, which brought about not only better enjoyment but also intensified engagement with the therapy.

StreetPong, What If You Were In..., Mood Squeezer and PhySeEar illustrate the relationship between play and wellbeing, both at an individual and at a collective level. Play is a good thing in itself, even if it does not lead to productive outcomes: it can make our lives more joyful, turn otherwise meaningless activities worth experiencing, and help us engage fully with the world [7]. Interestingly, as PhySeEar and Mood Squeezer show, that does not necessarily need to be at odds with productivity - even when this is not the ultimate goal of the play intervention.

\section{Play Allows Us to Have Agency}

Another relevant experiential quality of play is that it gives us agency - it allows us to choose, act and express ourselves in ways that are meaningful to us $[71,72]$. That can be very valuable in a world where people are increasingly busy and reliant on larger structures, which can provoke a feeling of lack of control of one's life [77,80]. Here we surface 4 ways in which playful technology afford agency: i) encouraging us to explore; ii) promoting critical thinking; iii) empowering us to act creatively; and iv) supporting self-awareness.

Re-framing situations as playful can spark curiosity, help us embrace uncertainty, and encourage us to explore the unknown $[50,76]$. As a result, play can open new avenues of action and create the necessary conditions for learning [10,75]: "as we toy with things and ideas, as we chat and daydream, we find new perspectives and new ways to create, new ambitions, relationships" [25]. Gaver's ludic design [25] implements this approach through the design of ambiguous mundane artifacts [26] that invite open-ended, self-guided exploration. For example, the Drift Table [27] (Figure 3A) is an electronic coffee table that slowly displays moving aerial footage mapped to the weight distribution of objects on its surface. Users can navigate across the footage by positioning parts of their body on the table. Importantly, this design is not meant to serve any productive agenda-it simply offers a chance for people to explore freely. A study

\footnotetext{
${ }^{3}$ Video of Newstweek: https://bit.ly/2T1WJRO
}

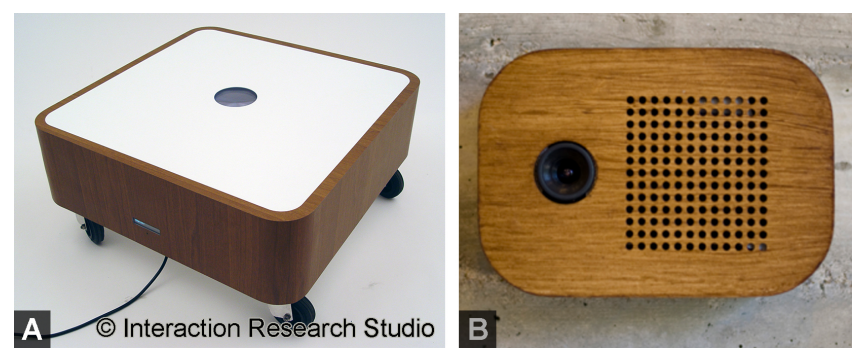

Figure 3. Playful technologies that afford exploration. A: the Drift Table [25]. B: the Speaker Prototypes [82].

revealed that people used the table "as an occasional break from their routine household activities" to "satisfy their curiosity and to wander, without feeling that it should be useful or utilitarian". The table brought people to explore together and augmented the experience of being around it, "encourage[ing] the exploration of new activities and appreciations" [27]. Bekker at al. have also designed technology to provoke curiosity, e.g. the Speaker Prototypes [82] (Figure 3B) were designed to explore how to promote self-guided playful exploration in public spaces. The interactive speakers respond to human presence and produce sounds that create "a situation that is clearly out-of-context" to "evoke curiosity through novelty" and invite people "to make sense of the situation." [82] A study showed that several "passers-by tried to find out 'how the system worked' and while doing this they discovered additional ways of interacting." [82] Researchers also observed that people "started discussing what they thought about the system, what they had heard from others, and so on." [82] The Speaker Prototypes show how playful technology can prompt people to explore, individually and collectively, and to experiment with new ways of engaging with space and with others.

By affording explorative behaviors, play can also promote critical thinking [34]: it can help us re-claim our desire to act in non-formulaic ways and break up entrenched social and cultural frames of behavior $[18,29,46]$. That is in itself a desirable value that society should cultivate - it empowers us to be autonomous and critical, and gives us opportunities to disrupt the state of affairs $[72,76]$. Playful technology has the capacity to afford that, e.g. Newstweek ${ }^{3}$ [63] (Figure 4), as described by Sicart in [72], enables individuals to playfully disrupt other people's news-reading in order to provoke collective critical thinking. It enables users to hack into wireless hotspots and manipulate the content of the news feeds read by people around them, offering average citizens

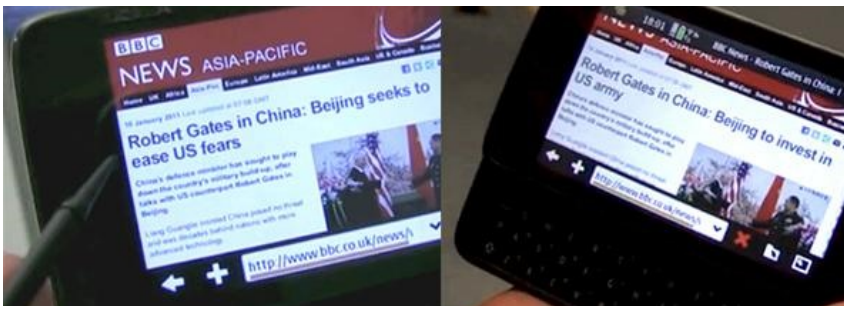

Figure 4. A news outlet, hacked through Newstweek [63]. 


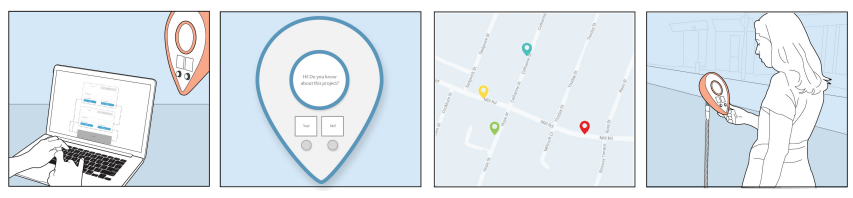

Figure 5. Basic functioning of Pinsight [52]. Left: how to add content to a Pin. Center-left: a Pin. Center-right: Pin locations on a map. Right: someone interacting with a Pin.

a chance to "have their turn to manipulate the press; generating propaganda or simply 'fixing facts." [63]

But play does not only promote exploration and critical thinking. It can also empower us to act creatively upon the world that surrounds us [72]. Play cultivates creative ideation [47]: "as we play, we think about thinking, and we learn to act in new ways." [87] That is, in part, because play is both appropriative and disruptive: it takes over the context where it happens and challenges the state of affairs [72]. Its "adaptive variability" [81] allows players to appropriate situations to suit their needs $[3,17]$. Being playful allows us to bring freedom to a context without disrupting it completely [72], which brings about the right conditions to create [76]. For example, Pinsight [52] (Figure 5) is a platform that supports average citizens to create and curate the content of tourist information points within their city, allowing them to have a (playful) say in their city's public image [52]. A study revealed that giving people a chance to become content creators led to richer connections between them and audiences (visitors): "participants were able to put themselves in the shoes of the public who might come across their content." [52] Although participants were not asked to write playful messages, that happened naturally: "most dialogues [...] had elements of wit and humor, for example, one person wrote a question: 'Do you know who lives next door?' with two possible answers: 'Can't get rid of them!' and 'Never seen them." [52] Pinsight shows how play "renews our natural sense of optimism and opens up to new possibilities" [7]: it prompted neighbors to collaborate by sharing "ideas, jokes, local history and local knowledge."

Play's capacity to promote critical thinking brings about an important social good: it is a wonderful way to connect with, be aware of, and reflect upon ourselves and our actions. Play is one of the activities that has more power over our character and nature [34]: it exposes us to our own contradictions, it reveals "the truest expression of our individuality" [7], and it exposes parts of ourselves that we often take for granted [72].

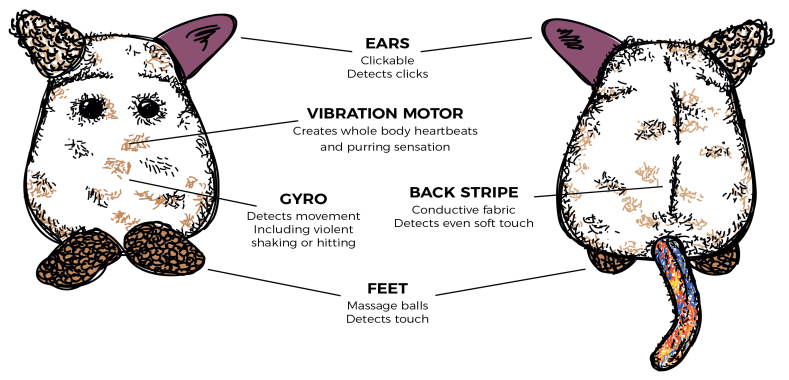

Figure 6. The Emotion Regulation Toy's [74] components.
As such, it is deeply relevant to human flourishing. Through play, we temporarily become whoever we want and act however we like. By "being outside of [ourselves] amongst the movements of play" [12] we reveal our desires and instincts [27] from a "dimension of experience that's between the subjective and the objective." [12] By making us curious, play helps us be proactive [57] and make sense of the world we live in [76]. It affords a safe space where we can reambiguate life and learn about it without putting ourselves at risk, transforming uncertainty into opportunities for learning and development [76]. The potential of play to promote selfawareness is very relevant to $\mathrm{HCI}$ - it can help us design technologies that not only improve experience, but also support reflection [25]. A design exemplar that illustrates this is the Emotion Regulation Toy [74] (Figure 6) that helps children calm down when they are anxious and learn to manage their own emotions. With a subtle haptic that mimics a rapid heartbeat, the toy invites the child to soothe it by hugging and patting it through simple fidgeting interactions [74] that are known to contribute to positive emotions and relaxation $[23,85]$. A user study demonstrated that playacting taking care of the creature invited figuring out what is "wrong" with it, which helped children better identify, understand, and deal with their negative emotions [74].

\section{Play Supports Social Affordances}

A third experiential quality of play is that it supports prosocial behavior $[45,55]$. This is relevant to HCI, as "social interaction is deeply consequential to human flourishing." [44] It is also particularly important in a contemporary society that suffers from an increasing lack of meaningful social connection [48]. Some argue that daily technology use might contribute to that problem, e.g. through screen-based interactions that distract people from the in-the-moment experiencing of co-located social interaction [35]. But technology does not necessarily need to isolate us. In fact, it can - and should - support and enrich our social lives. Play can be a useful strategy to do that, as it is known to have " $a$ positive impact on the well-being of both individuals and groups of people." [42] Here we discuss three ways in which playful technology can support social affordances: i) promoting coordinated action; ii) bringing people together; and iii) initiating meaningful connections.

Coordinated action makes people feel more connected and leads to mutual liking [44]. Playful technology can promote that, e.g. Keep-Up-With-Me [60] (Figure 7) enriches the social dimension of a meal by promoting synchronized eating between diners. Based on the amount of food left on the plates, these are lifted and lowered by a mechatronic

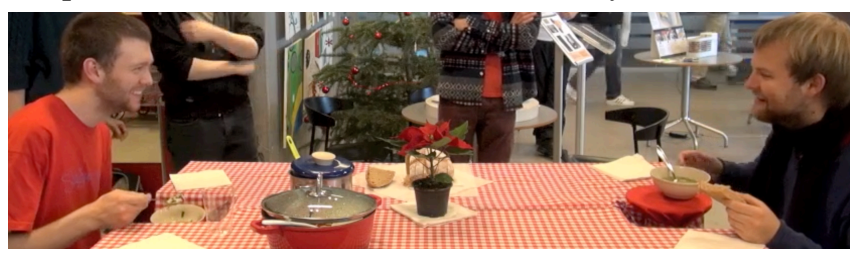

Figure 7. The Keep-Up-With-Me table [60]. One plate (left) is lower than the other (right) because its owner is eating faster. 

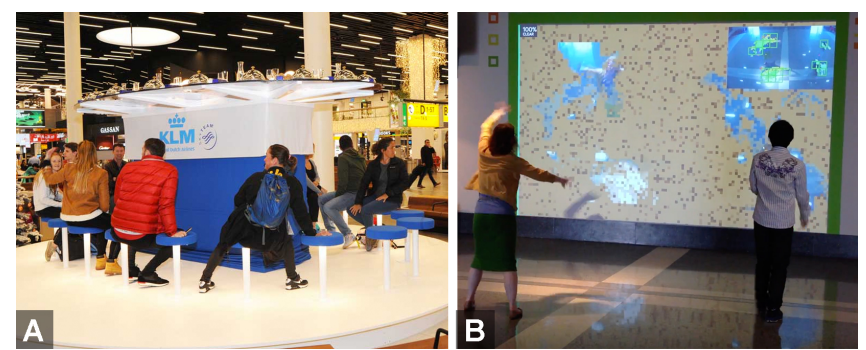

Figure 8. Playful technologies that bring people together. A: people sitting around the Bonding Buffet table [73], inviting others to sit. B: two persons playing with Pixel Motion [66].

table, augmenting cues people often use to pace their eating and balance it with social communication. It creates a playful disruption that invites, rather than forces, diners to be more aware of each other in a bizarre yet fun way.

Another pro-social behavior play may support is bringing people physically together [44]. That can be desirable in many situations where people share a physical space but do not interact directly, where people are alone, surrounded by strangers, and could benefit from the pleasure of social connection. Bonding Buffet ${ }^{4}$ [73] (Figure 8A) is an interactive installation designed by KLM Airlines to bring people together at airports. It consists of a dinner table surrounded by 20 chairs that can detect when people sit on them. When seats are not occupied, the table is lifted off the ground, making it difficult to see what is on it, and even to realize it is a table. As more people sit, the table lowers down, reaching the optimal height when all chairs are used. Bonding Buffet is meant to help strangers connect and enjoy each other's presence: "Every day, KLM flies thousands of passengers to all corners of the world, reuniting and connecting people with one another. But how do you ensure that people really sit down at a table together, engage with one another and share with each other?" [73]. According to a report, the mystery of discovering what was going on with that weird structure, the challenge of bringing together enough people to lower the table, and the reward of a shared dinner prompted people to collectively work together to share that meal: "People really enjoyed their time together at the table, with all sorts of new contacts emerging. It was so much fun, in fact, that we eventually had to remind some of the guests that they had flights to catch!" [73]. Bonding Buffet shows of how playful technology can bring us together and focus our attention towards each other while eating, instead of adding social barriers, which is often a criticism of technology use during meals [35]. Pixel Motion ${ }^{5}$ [66] (Figure $8 \mathrm{~B}$ ) is another installation designed to bring people together in public spaces, in this case a museum hall. It consists of a projection displayed on one of the walls of the hall, showing an opaque image overlaid to (and hiding) another. The image reacts to presence and movement: passersby can interact by wiping off areas of the opaque layer. Once the underlying

\footnotetext{
${ }^{4}$ Video of Bonding Buffet: https://bit.ly/2ijztMg
}

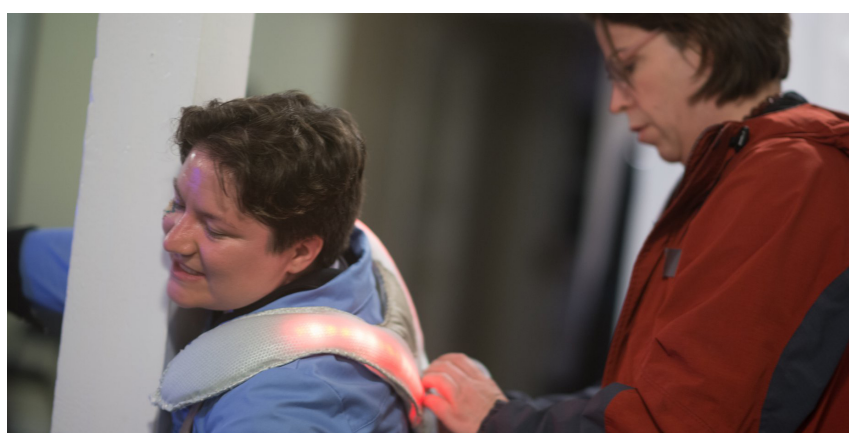

Figure 9. Playing with True Colors [15]: a wearer experiencing an overload (left) and a non-wearer helping overcome it (right).

image is uncovered, a photo of participants is taken as a reward. A study showed that the installation brought people together: "out of the 240 rounds observed, only a few were solo play, and approximately $85 \%$ of these in the presence of others" [66]. Seeing others play drew people to join: "when [...] visitors were standing to watch the display, their presence would tend to encourage other visitors, related or otherwise, to follow suit" [66].

Play does not only bring people together: it also creates the right conditions to initiate meaningful connections. True Colors $^{6}$ [15] (Figure 9) is a social wearable used in the diegetic universe of a live action role play game (LARP). The wearable gives special abilities (including stunning others), but it periodically puts the wear into a diegetic state of vulnerability (health crisis) that can be alleviated by copresent others through social touch on the back (reducing the time of crisis). A study revealed that this mechanism resulted in rich and unexpected social interactions [44]. Wearers barely used their attack function. Instead, they embraced and enjoyed the moments of crises: these urged non-wearers (even those taking antagonist roles in the LARP world) to initiate contact, and to gather and help in times of need, which was perceived by players as an important tool to initiate and deepen relationships.

Keep-Up-With-Me, Bonding Buffet, Pixel Motion and True Colors share a trait: they create the right conditions for social situations to emerge [44], inviting positive social and emotional action, and allowing those involved to enjoy the pleasure of meaningful social connections. We argue that this is a desirable social good technology should cultivate.

\section{DESIGN FEATURES: DESIGNING TECHNOLOGY FOR SITUATED AND EMERGENT PLAY}

Here we surface 5 recurrent design features in our collection of designs, in the form of actionable recommendations that can guide and inspire the design of future Technology for Situated and Emergent Play. They are connected to our design exemplars, and to previous intermediate-level contributions in the space of playful technology.

\footnotetext{
${ }^{5}$ Video of Pixel Motion: https://bit.ly/2MyY9Cl

${ }^{6}$ Video of True Colors: https://bit.ly/31jlxba
} 


\section{Playing Beyond Traditional Game Elements Enriches the} Social Experience

An important quality shared by the designs in our collection is that they hardly make use of traditional game elements (e.g. points, levels, etc.). They avoid the "aesthetics of meaningful choice," [71] or play-as-progress and play-asproblem-solving models that are usual in play-related HCI. Instead, they embrace a broader and more flexible idea of play. Even Pixel Motion [66], framed as a "public digital game," proposes a short and fast-paced play experience that focuses players on moving their bodies together rather than on progressing through the game. Instead of using scores or progress-oriented rewards, it focuses on "shaping the relationships between players," which is a powerful way to craft rich collocated play experiences [45]. StreetPong [21] also moves the focus away from progress rewards to emphasize the social dimension of the situation. Like in Pixel Motion, the play experience does not transcend the scope of a round (e.g. through a ranking); instead, the reward is the very act of crossing paths with the stranger with whom you just played. These examples illustrate how playing beyond traditional game elements might be an interesting strategy to promote spontaneous moments of joy and social interaction.

Playful Objects Re-Signify "Serious" Spaces and Norms The technologies in our collection inhibit mundane spaces and integrate well in their contextual objects. Embedding playful artifacts in "serious" spaces can support playful resignification of those spaces, and of situated cultural norms [37]. That re-appropriation can happen in different ways:

First, we see technologies that disrupt the state of affairs in "serious" situations. For example, by augmenting structural elements of a space to turn it into a momentary playground, e.g. StreetPong [21] adds a game interface to traffic light poles to prompt passersby to be playful in the street. Other designs augment everyday objects to re-signify concrete routine activities, e.g. the Keep-Up-With-Me table [60] turns the action of putting food into one's mouth into a playful and social activity. Mitchell et al. [60] acknowledge the potential of building on existing actions to augment a situation playfully: "the activity of collecting food from the dish was the point of departure [...]. This very aspect is crucial to successfully empower or enrich existing practices of eating, in contrast to imposing technology or augmenting objects with additional functionalities". This resonates with responses to recent calls for increasingly situated approaches to play design, like our proposal to identify play potentials (i.e. existing interactions that are, or have the potential of becoming, playful) and use them as design material [2].

Second, we see technology-augmented objects that promote playful behaviors without directly disrupting the activities taking place in those situations, e.g. Mood Squeezer [24] promotes playful behaviors to encourage rethinking cultural norms, but it does that at times of the participants' choosing, in a way that it does not interfere directly with the normal activities taking place at the office. The coffee Drift Table [27] follows a similar principle: it allows users to interact with the virtual footage whenever they want, but it does not prevent them from ignoring the technological augmentation if they would like.

Finally, we see designs where promoting a playful reappropriation of an activity supports the "serious" actions expected in that activity. Those examples introduce technology as an object that is instrumental for the activity. For example, in PhySeEar [54] the robot plays a key role in the ongoing activity (e.g. guiding and giving feedback about movements) while also supporting collective playful resignification (e.g. its anthropomorphic looks and strict behavior support antagonizing and siding; its clumsy movements support teasing [54]).

Flexibility of Interaction Diversifies the Play Experience Flexibility of interaction can lead to a richer palette of play experiences, as it affords multiple ways of engaging withand through - technology and gives users a chance to experience it in radically different ways. It also allows play to transpire alongside, or within, real-life activities, supporting and augmenting - rather than disrupting - the inthe-moment engagement with those activities. In our collection, we see different ways to achieve that:

First, affording the emergence of user-driven, contextually meaningful interactions, e.g. rather than imposing specific ways of interacting, Keep-Up-With-Me [60] allows users to determine their own ways of being playful: collaborating to eat comfortably, competing to finish first, pranking each other... The Drift Table [27] can also be interacted with in different ways, even by people who use it simultaneously. That open-endedness facilitates appropriation: "people found their own means to accommodate the table to their own routines [...] in a variety of ways." [27] Creating space for playful appropriation can help promote "improvisation and performance." [45] Empowering people to playfully appropriate the experience rather than imposing a specific way to play allows them to engage in ways that feel meaningful and align well with their ongoing activities.

Second, allowing players to jump in-and-out of the play experience easily, e.g. Pixel Motion [66] blurs the difference in the roles of players and spectators by allowing people to participate by simply being present in the space. It creates a porous magic circle that allows people to commit in different ways and with varying levels of intensity. According to the authors, that "fluid boundary between player and observer [...] seemed to reduce the barrier to participation." [66] Porous magic circles create the right conditions for explorative engagement, e.g. What If You Were In... [1] allows passersby to choose between walking closer and being featured on screen, or staying at a distance and seeing how others "travel where they would rather be." Both Pixel Motion and What If You Were In... open up opportunities for different levels of engagement depending on people's intentions and allow them to modify their role as the experience unfolds. By embracing varying levels of commitment, they increase the chances that not only those 
who are naturally attracted to play participate. They also make the experience visible to (and intriguing for) spectators, which is known to be an interesting strategy to attract new participants in co-located play experiences [45].

\section{Ambiguous Interfaces Elicit Curiosity}

Ambiguous interfaces promote explorative engagement [26] through internal complexity [37]. This design feature has been explored before in HCI, especially by Gaver et al. [26], who proposed different ways in which ambiguity can be used as a design resource. In our collection of playful technologies we see different kinds of ambiguity represented:

First, the Drift Table [27] creates ambiguity of relationship [26] between users the technology, disrupting the common uses of a coffee table and offering new ways of interacting with it. As a result, it leads to emergent interactions: "in deliberately withholding a clear interpretation or narrative of use," it allows "people to find their own meanings and uses for it" [27]. Similarly, Mood Squeezer [24] does not provide clear instructions: it simply invites users to express their mood by squeezing a colored sphere of their choosing. By not imposing an exact color-emotion mapping, it allows people to interpret freely and creates opportunities for casual social interaction: "the deliberate open ended mapping between mood and color often acted as a point of discussion" [24]. Second, Mood Squeezer also uses ambiguity of context [26]: it brings an object that is clearly playful - the squeezy spheres - to a "serious" context, creating a tension that draws people to interact and facilitates a playful re-signification of the space. Finally, playfulness can also derive from ambiguity of information [26], e.g. Newstweek [63] allows users to disrupt the contents of online news feeds and create inconsistencies in the information, prompting others to interpret the causes behind those inconsistencies and reflect on their position with regards to the information.

\section{Unexpected Disruptions Encourage People to Let Go}

The last design quality shared by designs in our collection is the use of spontaneous moments of disruption to facilitate the emergence of play, make people curious, and encourage them to participate. The Speaker Prototypes [82] illustrate how estrangement can open space for playful engagement that seasons otherwise unstimulating scenarios "by creating a situation that is clearly out-of-context" and "evokes curiosity through novelty." The idea of using a strange, unexpected situations to attract people is also key to Bonding Buffet [73]. In this case, the playful disruption has additional effects: it brings people together and encourages them to initiate contact. That is also true for True Colors [15], which periodically puts the wearer into a diegetic state of vulnerability that opens a window of opportunity for social and playful engagement between people: non-wearers can offer their help as a starting point of social interaction. Mood Squeezer [24] also uses oddity to bring people together: it attracts people through a series of out-of-context spheres that can be squeezed-an interaction that can be seen as pleasurable. The spheres disrupt the common setup of the office and call to action by presenting themselves as something new and exciting: "They reminded [participants] of childhood toys and the bright colors of the balls engendered feelings of being light-hearted. It encouraged them to spontaneously be playful around them." [24]

\section{DISCUSSION}

The experiential qualities in this paper are in alignment with important societal values. They synthesize knowledge extensively discussed by play designers and theorists that might not have been fully embraced in HCI yet: play is a desirable social good that adds value in many areas of human life, and can have positive effects on individuals and groups. In a world where technology is increasingly present, designing it to only respond to productive agendas can have profound negative effects, neglecting experiences that are key to our well-being.

While being productive is an important dimension of human life, it is (at least) equally important to take care of our socioemotional needs [9]. That leads us to back Burkeman's concern that rejecting productivity in favor of play can be a radical act [9] — while that might be true today, why should it be? Brown argues that "remembering what play is all about and making it part of our daily lives are probably the most important factors in being a fulfilled human being" [7]. Our bridging concept suggests that Technology for Situated and Emergent Play can help us do that, encouraging and supporting us in playing every day, in and beyond the realm of entertainment games. Surely, technology can help us be more productive, but it should also augment the in-themoment experience of our daily lives.

Importantly, when aiming to support people to be playful, we face the question of whether technology is needed. Indeed, technology is not necessary for play to emerge - people can be playful with and without it. But technology is increasingly present in our lives and it shapes our attitude towards, engagement with, and experience of the world. Our work complements others on dedicated technology-mediated play. Here we focus on technology that fits well with our everyday activities, seasoning them through supporting the emergence of playful engagement that can be socio-emotionally desirable. We argue that the qualities foregrounded in this paper should be considered by HCI designers even more than they are today. Designers have the opportunity - and, we argue, the responsibility - to design technologies that help us flourish individually and collectively.

Our bridging concept shows different ways in which technology for play can escape the productivity hype. It unpacks design strategies to afford playful engagement for its inherent positive effects, regardless of specific productive gains. Yet, our contribution does not dismiss play's potential to support those too. Playing "just because" does not need to be at odds with productivity [56], like PhySeEar [54] illustrates. In fact, play can be a catalyst whose benefits "spread throughout our lives, actually making us more productive and happier in everything we do." [7] Here,we 
foreground reasons why, and show how, designing to support non-productive playfulness can add value, even outside of leisure.

Regarding scope and limitations of our work, some are contestably inherent to the nature of intermediate-level knowledge [16]. As pointed out by one reviewer, our bridging concept is less well encapsulated and "tangible" than the peepholes example in Dalsgaard and Dindler's seminal bridging concepts paper [16]. Yet, our Technology for Situated and Emergent Play concept "inhabits the middle ground between theory and practice" and aims to "bridge the gap between" them [16]. Further, it fulfills the three main components of bridging concepts (theoretical foundations, design articulations, and design exemplars) and their roles. Hence, given the provisional, contingent and aspirational nature of early theory in design HCI [28], we argue for the need to allow a variety of bridging concepts to emerge and the design research community to collectively evolve and further specify what bridging concepts are.

Then, as a bridging concept, our contribution is generative, unstable, transitional and incomplete: It does not offer a solid understanding of all possible socio-emotional effects of play(fulness), nor provides a definitive set of relevant design features to play design. Neither does it cover the full breadth of literature on play, nor all types of playful technologies. Rather, it unpacks salient aspects within a specific design space; focuses on research-motivated design exemplars rather than commercial ones; and make more accessible, relevant, and actionable a relevant theoretical foundation that can inspire the design of playful technology in ways that are currently underrepresented in $\mathrm{HCI}$.

Another limitation of this work is that it focuses on the positive socio-emotional effects of playful engagement. As pointed out by a reviewer, play can also have negative effects - even the exemplars we analyzed could potentially lead to interactions that are socio-emotionally counterproductive. For example, having a chance to do humorous remarks about one's neighbors through Pinsight could be a platform for toxic social behavior. More research is needed to fully investigate all effects - positive and negative - of Technology for Situated and Emergent Play.

It also remains future work for us-we encourage others to join us in this endeavor - to investigate how exactly the design articulations above can drive design processes. While some of the design exemplars in our repertoire clearly aimed for certain experiential qualities and/or used concrete design features as starting point (e.g. [27,66]) many others highlight experiential qualities and design features that emerged, and were found particularly useful, in interaction. This is quite common in Research through Design work, wherein design research knowledge is produced while designing and in interaction [28]. It is also common - and productive - in the design space of Technology for Situated and Emergent Play. Last, we conclude reinforcing the call for future intermediate-level works that explore how designers can embrace the emergent, dynamic and often unpredictable nature of play design practice [2]. We work to set the first steps in that direction.

\section{CONCLUSION}

This paper presents a bridging concept characterizes the design space of technology design that supports the emergence of play outside leisure, interwoven with our everyday practices and activities, seasoning them and supporting social and emotional engagement. Our concept, Technology for Situated and Emergent Play, makes accessible a theoretical foundation in the form of two design articulations: experiential qualities of play that are desirable from a socio-emotional perspective, and design features that can support those qualities. They are grounded in and illustrated through a collection of design exemplars.

We presented 3 valuable experiential qualities of play that respond to fundamental social and emotional needs. We showed how, through playful technology, we can: i) add joy to mundane situations; ii) afford agency to explore, create and reflect; and iii) facilitate meaningful social connections. Play can be a source of positive emotions: it re-frames meaningless situations into memorable ones, e.g. What If You Were In... [1]; it seasons serious contexts with spontaneous moments of joy, e.g. PhySeEar [54]; and it gives us chances express ourselves by sharing our thinking and feelings with others, e.g. Mood Squeezer [24]. Play can also provide us with a feeling of agency: it creates the right conditions to explore, e.g. the Drift Table [27]; it encourages us to think critically, and provoke others to do so, e.g. Newstweek [63]; it empowers us to have creative input into the world that surrounds us, e.g. Pinsight [52]; and it helps us to reflect and get to know ourselves better, e.g. the Emotion Regulation Toy [74]. Further, play can also respond to our social cravings: it gives us reasons to get together, e.g. Bonding Buffet [73]; to empathize with one another, e.g. Keep-Up-With-Me [60]; and to initiate meaningful social connections, e.g. True Colors [15].

We also presented 5 inspiring design features in the form of recommendations that can guide the design of future Technology for Situated and Emergent Play: i) transcending traditional game elements; ii) using playful objects to resignify serious situations; iii) affording flexibility of interaction; iv) using ambiguity to elicit curiosity; and v) creating unexpected disruptions that help people to let go. Our contribution has both synthetic and inspirational value: it weaves together existing play and play design theories, it extends the set of proposed design articulations, it bridges theoretical constructs and design exemplars, and it discusses key design features that can inspire future playful technologies that better respond to people's socio-emotional needs. We hope that it will facilitate the design of future technologies that make it acceptable to engage in playful ways that, as we have seen, can have desirable effects on our individual and collective well-being. 


\section{REFERENCES}

[1] Ferran Altarriba Bertran and James Miller. 2014. What if you were in.... Retrieved on November 30, 2018 from http://ferranaltarriba.com/projects/wiywi/

[2] Ferran Altarriba Bertran, Elena Márquez Segura, Jared Duval, and Katherine Isbister. 2019. Chasing Play Potentials: Towards an Increasingly Situated and Emergent Approach to Everyday Play Design. In Proceedings of the 2019 Designing Interactive Systems Conference 2019. ACM.

[3] Jon Back, Elena Márquez Segura, and Annika Waern. 2017. Designing for Transformative Play. ACM Trans. Comput.-Hum. Interact. 24, 3: 18:1-18:28. https://doi.org/10.1145/3057921

[4] Susanne Bødker. 2006, October. When second wave HCI meets third wave challenges. In Proceedings of the 4th Nordic conference on Human-computer interaction: changing roles (pp. 1-8). ACM.

[5] Susanne Bødker. 2015. Third-wave HCI, 10 years later---participation and sharing. Interactions, 22(5), 24-31.

[6] Ian Bogost. 2016. Play anything: The pleasure of limits, the uses of boredom, and the secret of games. Basic Books.

[7] Stuart L. Brown. 2009. Play: How it shapes the brain, opens the imagination, and invigorates the soul. Penguin.

[8] Barry Brown and Oskar Juhlin. 2015. Enjoying machines. Mit Press.

[9] Oliver Burkeman. 2018. The Promise of Play. NewPhilosopher, Issue 20, May-July 2018.

[10] Roger Caillois. 2001. Man, play, and games. University of Illinois Press.

[11] Nuno Castelhano and Licínio Roque. 2017. Lessons From Designing a Game to Support Playfulness in Multisensory Stimulation Environments. In Proceedings of the Annual Symposium on Computer-Human Interaction in Play (CHI PLAY '17). ACM, New York, NY, USA, 57-68. DOI: https://doi.org/10.1145/3116595.3116599

[12] Simon Critchley. 2018. Being Outside of Yourself. NewPhilosopher, Issue 20, May-July 2018.

[13] João P. Costa, Rina R. Wehbe, James Robb, and Lennart E. Nacke. 2013. Time's up: studying leaderboards for engaging punctual behaviour. In Proceedings of the First International Conference on Gameful Design, Research, and Applications (Gamification '13). ACM, New York, NY, USA, 26-33. DOI=http://dx.doi.org/10.1145/2583008.2583012
[14] Mihaly Csikszentmihalyi. 1997. Finding flow: The psychology of engagement with everyday life. Basic Books.

[15] Ella Dagan, Elena Márquez Segura, Ferran Altarriba Bertran, Miguel Flores, and Katherine Isbister. In Press. Designing 'True Colors': A Social Wearable that Affords Vulnerability. In Proceedings of the 2019 CHI Conference on Human Factors in Computing Systems (CHI '19).

[16] Peter Dalsgaard and Christian Dindler. 2014. Between theory and practice: bridging concepts in HCI research. In Proceedings of the SIGCHI Conference on Human Factors in Computing Systems (CHI '14). ACM, New York, NY, USA, 1635-1644.

DOI=http://dx.doi.org/10.1145/2556288.2557342

[17] Bernard DeKoven. 2013. The Well-Played Game: A Player's Philosophy. The MIT Press, Cambridge, MA, USA.

[18] Sebastian Deterding. 2009. The Game Frame: Systemizing a Goffmanian Approach to Video Game Theory.

[19] Sebastian Deterding, Dan Dixon, Rilla Khaled, and Lennart Nacke. 2011. From game design elements to gamefulness: defining "gamification". In Proceedings of the 15th International Academic MindTrek Conference: Envisioning Future Media Environments (MindTrek '11). ACM, New York, NY, USA, 9-15. DOI: https://doi.org/10.1145/2181037.2181040

[20] Sebastian Deterding. 2015. A Manifesto, With Footnotes. A Review of Miguel Sicart's "Play Matters". Game Studies, 15(1).

[21] Fred O. Donaldson and Ole V. Lassen. 2002. Playing by heart: The vision and practice of belonging. Danmarks Blindebibliotek.

[22] Sandro Engel and Amelie Künzler. 2012. StreetPong. Retrieved on November 16, 2018 from http://www.streetpong.info.

[23] Traci L. Galinsky, Roger R. Rosa, Joel S. Warm, and William N. Dember. 1993. Psychophysical Determinants of Stress in Sustained Attention. Human Factors 35, 4: 603-614. https://doi.org/10.1177/001872089303500402

[24] Sarah Gallacher, Jenny O'Connor, Jon Bird, Yvonne Rogers, Licia Capra, Daniel Harrison, and Paul Marshall. 2015. Mood Squeezer: Lightening up the Workplace through Playful and Lightweight Interactions. In Proceedings of the 18th ACM Conference on Computer Supported Cooperative Work $\&$ Social Computing (CSCW '15). ACM, New York, NY, USA, 891-902. DOI: https://doi.org/10.1145/2675133.2675170 
[25] Bill Gaver. 2002. Designing for Homo Ludens. I3 Magazine 12. Retrieved from https://www.gold.ac.uk/media/documentsbysection/departments/research-centresandunits/research-units/interactionresearchstudio/27gaver.ludens.02.pdf

[26] William W. Gaver, Jacob Beaver, and Steve Benford. 2003. Ambiguity as a resource for design.

In Proceedings of the SIGCHI Conference on Human Factors in Computing Systems (CHI '03). ACM, New York, NY, USA, 233-240.

DOI=http://dx.doi.org/10.1145/642611.642653

[27] William W. Gaver, John Bowers, Andrew Boucher, Hans Gellerson, Sarah Pennington, Albrecht Schmidt, Anthony Steed, Nicholas Villars, and Brendan Walker. 2004. The drift table: designing for ludic engagement. In CHI '04 Extended Abstracts on Human Factors in Computing Systems (CHI EA '04). ACM, New York, NY, USA, 885-900. DOI: https://doi.org/10.1145/985921.985947

[28] William Gaver. 2012. What should we expect from research through design?. In Proceedings of the SIGCHI Conference on Human Factors in Computing Systems (CHI '12). ACM, New York, NY, USA, 937946. DOI: https://doi.org/10.1145/2207676.2208538

[29] Erving Goffman. 1986. Frame Analysis: An Essay on the Organization of Experience. Northeastern University Press.

[30] Melissa Gregg. 2011. Work's Intimacy. Polity Press, Cambridge, UK.

[31] Melissa Gregg. 2014. Presence Bleed: Performing Professionalism Online. Retrieved January 4, 2019 from https://www.academia.edu/1513344/Presence_Bleed_P erforming_Professionalism_Online

[32] Begoña Gros. 2007. Digital games in education: The design of games-based learning environments. Journal of research on technology in education, 40(1), 23-38.

[33] Lars Hallnäs and Johan Redström. 2001. Slow Technology - Designing for Reflection. Personal Ubiquitous Comput. 5, 3 (January 2001), 201-212. DOI=http://dx.doi.org/10.1007/PL00000019

[34] Luther Halsey Gulick. 1920. A philosophy of play. McGrath Publishing Company.

[35] Deepi Harish. 2017. \#FoodPorn Is Changing The Way Millennials Eat. In Huffington Post. Published on March 24th, 2017. Accessed on October 23rd, 2018 at https://www.huffingtonpost.ca/deepi-harish/foodporneating-habits_b_15574714.html

[36] Steve Harrison, Deborah Tatar, and Phoebe Sengers. 2007, April. The three paradigms of HCI. In Alt. Chi. Session at the SIGCHI Conference on Human Factors in Computing Systems San Jose, California, USA (pp. 1-18).

[37] Mads Hobye. 2014. Designing for Homo Explorens: open social play in performative frames. Faculty of Culture and Society Malmö University.

[38] Kristina Höök and Jonas Löwgren. 2012. Strong concepts: Intermediate-level knowledge in interaction design research. ACM Transactions on ComputerHuman Interaction (TOCHI), 19(3), 23.

[39] Kristina Höök, Martin P. Jonsson, Anna Ståhl, and Johanna Mercurio. 2016. Somaesthetic Appreciation Design. In Proceedings of the 2016 CHI Conference on Human Factors in Computing Systems (CHI '16), 3131-3142. https://doi.org/10.1145/2858036.2858583

[40] Kristina Höök, Baptiste Caramiaux, Cumhur Erkut, Jodi Forlizzi, Nassrin Hajinejad, Michael Haller, Caroline C. M. Hummels, Katherine Isbister, Martin Jonsson, George Khut, Lian Loke, Danielle Lottridge, Patrizia Marti, Edward Melcer, Florian Floyd Müller, Marianne Graves Petersen, Thecla Schiphorst, Elena Márquez Segura, Anna Ståhl, Dag Svanæs, Jakob Tholander, and Helena Tobiasson. 2018. Embracing First-Person Perspectives in Soma-Based Design. Informatics 5, 1: 8. https://doi.org/10.3390/informatics5010008

[41] Xiyuan Hou and Olga Sourina. 2013. Emotion-enabled haptic-based serious game for post stroke rehabilitation. In Proceedings of the 19th ACM Symposium on Virtual Reality Software and Technology (VRST '13). ACM, New York, NY, USA, 31-34. DOI: https://doi.org/10.1145/2503713.2503738

[42] Johan Huizinga. 1950. Homo Ludens: A Study of the Play Element in Culture. Beacon Press.

[43] Katherine Isbister. 2011. Emotion and Motion: Games As Inspiration for Shaping the Future of Interface. interactions 18, 5: 24-27. https://doi.org/10.1145/2008176.2008184

[44] Katherine Isbister. 2016. How games move us: Emotion by design. MIT Press.

[45] Katherine Isbister, Elena Márquez Segura, and Edward F. Melcer. 2018. Social Affordances at Play: Game Design Toward Socio-Technical Innovation. In Proceedings of the 2018 CHI Conference on Human Factors in Computing Systems (CHI '18). ACM, New York, NY, USA, Paper 372, 10 pages. DOI: https://doi.org/10.1145/3173574.3173946

[46] Jaakkoo Stenros. 2012. In Defence of a Magic Circle: The Social and Mental Boundaries of Play. In DIGRA 2012. Retrieved from http://www.digra.org/wpcontent/uploads/digital-library/12168.43543.pdf

[47] Carl Gustav Jung. 1924. Psychological types. New York. 
[48] Druv Khullar. 2016. How social isolation is killing us. New York Times, Dec 22, 2016.

[49] Carol Kranowitz. 2006. The Out-of-Sync Child Has Fun, Revised Edition: Activities for Kids with Sensory Processing Disorder. Penguin.

[50] Nicole Lazzaro. 2004. Why we play games: Four keys to more emotion without story.

[51] Conor Linehan, Sabine Harrer, Ben Kirman, Shaun Lawson, and Marcus Carter. 2015. Games Against Health: A Player-Centered Design Philosophy. In Proceedings of the 33rd Annual ACM Conference Extended Abstracts on Human Factors in Computing Systems (CHI EA '15). ACM, New York, NY, USA, 589-600. DOI: https://doi.org/10.1145/2702613.2732514

[52] Can Liu, Ben Bengler, Danilo Di Cuia, Katie Seaborn, Giovanna Nunes Vilaza, Sarah Gallacher, Licia Capra, and Yvonne Rogers. 2018. Pinsight: A Novel Way of Creating and Sharing Digital Content through 'Things' in the Wild. In Proceedings of the 2018 Designing Interactive Systems Conference (DIS '18). ACM, New York, NY, USA, 1169-1181. DOI: https://doi.org/10.1145/3196709.3196782

[53] Jonas Löwgren. 2013. Annotated portfolios and other forms of intermediate-level knowledge. Interactions, 20(1), 30-34.

[54] Elena Márquez Segura, Annika Waern, Luis Márquez Segura, and David López Recio. 2016. Playification: The PhySeEar case. In Proceedings of the 2016 Annual Symposium on Computer-Human Interaction in Play (CHI PLAY '16). ACM, New York, NY, USA, 376388. DOI: https://doi.org/10.1145/2967934.2968099

[55] Elena Márquez Segura, James Fey, Ella Dagan, Samvid Niravbhai Jhaveri, Jared Pettitt, Miguel Flores, and Katherine Isbister. 2018. Designing Future Social Wearables with Live Action Role Play (Larp) Designers. In Proceedings of the 2018 CHI Conference on Human Factors in Computing Systems (CHI '18). ACM, New York, NY, USA, Paper 462, 14 pages. DOI: https://doi.org/10.1145/3173574.3174036

[56] Joe Marshall and Conor Linehan. 2017. Misrepresentation of Health Research in Exertion Games Literature. In Proceedings of the 2017 CHI Conference on Human Factors in Computing Systems (CHI '17). ACM, New York, NY, USA, 4899-4910. DOI: https://doi.org/10.1145/3025453.3025691

[57] Jane McGonigal. 2011. Reality is broken: Why games make us better and how they can change the world. Penguin.

[58] Karl Meier. 1980. An Affair of Flutes: An Appreciation of Play. Journal of the Philosophy of Sport, 7:1, 24-45.
[59] David R. Michael and Sandra Chen. 2005. Serious games: Games that educate, train, and inform. Muska \& Lipman/Premier-Trade.

[60] Robb Mitchell, Alexandra Papadimitriou, Youran You, and Laurens Boer. 2015. Really eating together: a kinetic table to synchronise social dining experiences. In Proceedings of the 6th Augmented Human International Conference (AH '15). ACM, New York, NY, USA, 173-174. DOI: http://dx.doi.org/10.1145/2735711.2735822

[61] Ivan Mosca. 2012. + 10! Gamification and Degamification. $G|A| M \mid E$ Games as Art, Media, Entertainment, 1(1).

[62] Casey O'Donnell. 2014. Getting played: Gamification, bullshit, and the rise of algorithmic surveillance. Surveillance \& Society, 12(3), 349.

[63] Julian Oliver and Danja Vasiliev. 2011. Newstweek. Retrieved on November 12, 2018 from https://newstweek.com.

[64] Ash Perrin. 2018. The Power of Play. TEDx Talks. Retrieved on November 30, 2018 from https://www.youtube.com/watch?v=VNAtVKLxjnA.

[65] Rey, P. J. (2015). Gamification and post-fordist capitalism. The gameful world: Approaches, issues, applications, 277-296.

[66] Holly Robbins and Katherine Isbister. 2014. Pixel Motion: A surveillance camera-enabled public digital game. In FDG.

[67] Bertrand Russell. 1932. In Praise of Idleness.

[68] Eric Sanchez, Shawn Young and Caroline JouneauSion. 2017. Classcraft: from gamification to ludicization of classroom management. Education and Information Technologies , 22(2), 497-513.

[69] Greg Satell. 2013. What Can We Expect From The Next Decade of Technology?. In Forbes. Retrieved on January 4, 2019 from https://www.forbes.com/sites/gregsatell/2013/06/29/wh at-can-we-expect-from-the-next-decade-of-technology

[70] Kieran Setiya. 2017. Midlife: A Philosophical Guide. Princeton University Press.

[71] John Sharp and David Thomas. 2019. Fun, Taste, \& Games: An Aesthetics of the Idle, Unproductive, and Otherwise Playful. MIT Press.

[72] Miguel Sicart. 2014. Play matters. MIT Press.

[73] Dewi Simon. 2016. Dinner with twenty fellow travellers. In blog.klm.com. Retreived on January 2, 2019 from https://blog.klm.com/dinner-with-twentyfellow-travellers/

[74] Petr Slovák, Nikki Theofanopoulou, Alessia Cecchet, Peter Cottrell, Ferran Altarriba Bertran, Ella Dagan, Julian Childs, and Katherine Isbister. 2018. "I just let him cry...: Designing Socio-Technical Interventions in 
Families to Prevent Mental Health Disorders. Proc. ACM Hum.-Comput. Interact. 2, CSCW, Article 160 (November 2018), 34 pages. DOI: https://doi.org/10.1145/3274429

[75] Ed Smith. 2018. Play Like a Child. NewPhilosopher, Issue 20, May-July 2018.

[76] Henrik Sproedt. 2012. Play. Learn. Innovate. Books on Demand.

[77] J. Staff. 2014. Why is everyone so busy. The Economist. Retrieved from http://www. economist. com/news/christmasspecials/21636612-time-povertyproblempartly-perception-and-partly-distributionwhy.

[78] Jaakko Stenros. 2014. In defence of a magic circle: the social, mental and cultural boundaries of play.

[79] Bernard Suits. 1978. The Grasshopper: Games, Life, and Utopia.

[80] Pekka Sulkunen. 2009. The saturated society: Governing risk \& lifestyles in consumer culture. Sage Publications.

[81] Brian Sutton-Smith. 2009. The ambiguity of play. Harvard University Press.

[82] Rob Tieben, Tilde Bekker, and Ben Schouten. 2011. Curiosity and interaction: making people curious through interactive systems. In Proceedings of the 25th BCS Conference on Human-Computer Interaction (BCS-HCI '11). British Computer Society, Swinton, UK, UK, 361-370.
[83] Mattia Thibault. 2017. Play as a Modelling System - a Semiotic Analysis of the Overreaching Prestige of Games. In GamiFIN Conference 2017, Pori, Finland, May 9-10, 2017.

[84] Debbe Thompson, Tom Baranowski, Richard Buday Janice Baranowski, Victoria Thompson, Russell Jago and Melissa Juliano Griffith. 2010. Serious video games for health: How behavioral science guided the development of a serious video game. Simulation \& gaming, 41(4), 587-606.

[85] Alfonso Troisi, Sergio Belsanti, Anna R. Bucci, Cristina Mosco, Fabiola Sinti, and Monica Verucci. 2000. Affect regulation in alexithymia: an ethological study of displacement behavior during psychiatric interviews. The Journal of Nervous and Mental Disease 188, 1: 13-18.

[86] Stacey Watson, Julio César Bahamón, Harini Ramaprasad, and Heather Richter Lipford. 2018. Developing Soft Skills with a Classroom Behavior Management Game. In Proceedings of the 49th ACM Technical Symposium on Computer Science Education (SIGCSE '18). ACM, New York, NY, USA, 1092-1092. DOI: https://doi.org/10.1145/3159450.3162247

[87] Eric Zimmerman. 2015. Manifesto for a ludic century. The gameful world: Approaches, issues, applications, 19-22. 